\title{
Gastronomi Turizmi Üzerine Bir Literatür İncelemesi
}

\author{
A Literature Review about Gastronomy Tourism
}

\author{
Mehmet SARIIŞIK*, Gülçin ÖZBAY** \\ *Prof. Dr., Sakarya Üniversitesi, Işletme Fakültesi, Turizm Işletmeciliği Bölümü, Esentepe Kampüsü, 54187, Serdivan, Sakarya. \\ E-posta: msariisik@sakarya.edu.tr \\ **Öğr. Gör. Dr., Sakarya Üniversitesi, Kırkpınar Turizm Meslek Yüksek Okulu, Hasanpaşa Mah. Fatih Cad. No:4, 54600, Kırkpınar,Sapanca, \\ Sakarya. \\ E-posta: gozbay@sakarya.edu.tr
}

\section{MAKALE BILGILERI \\ Makale işlem bilgileri: \\ Gönderilme tarihi: 6 Şubat 2014 \\ Birinci değerlendirme: 15 Nisan 2014 \\ İkinci değerlendirme: 26 Mayıs 2014 \\ Üçüncü değerlendirme: 11 Temmuz 2014 \\ Kabul: 7 Ağustos 2014}

Anahtar sözcükler:

Anahtar sözcükler: Turizm, Yiyecek ve

içecek, Gastronomi, Gastronomi turizmi.
ÖZ

Bu çalışma, gastronomi turizmine ilişkin mevcut yazının taramasıdır. Son on yılda konuya ilişkin araştırma sayısının artması bu alana gösterilen ilginin bir kanıtı durumundadır. Bununla birlikte gastronomi turizminin tanımı ve kapsamı açısından tartışmalar devam etmektedir. Yapılan araştırmalar özellikle kırsal alanlardaki turizm içerisinde gastronominin etkinliği ve pazarlama açısından önemi üzerine yoğunlaşmaktadır. Farklı destinasyonların gastronomi turizmi açısından karşılaştırılması ve gastronomi ile kültür turizmi bağlantıları incelenen diğer konular arasındadır. Ayrıca gastronomi turizmi tanım denemeleri ve kapsamı konusu ele alınmıstır. Turizmden aldığı payı arttırma amacındaki ülkeler ve bölgeler yeni pazar oluşturmak için bu alana yönelmeye başlamışlardır. Ancak gastronomi turizmi ya da bunu önemli motivasyon gerekçeleri arasında değerlendiren seyahatçilerin iyi incelenmesi gerekmektedir.

\section{ARTICLE INFO}

Article history:

Submitted: 6 February 2014

Resubmitted: 15 April 2014

Resubmitted: 26 May 2014

Resubmitted: 11 July 2014

Accepted: 7 August 2014

Key words:

Tourism, Food and beverage,

Gastronomy, Gastronomy tourism.

\section{ABSTRACT}

This research is a literature review about gastronomy tourism. The increase in research in this field proves that there is a growing interest in gastronomy tourism. Moreover, definitions and concepts of gastronomy tourism still have been discussed. Previous research has concentrated especially in the effects of gastronomy and the importance of it in marketing destinations. Others are related to the definitions and the concept of gastronomy tourism. The countries and regions that want to increase their tourism share have begun to focus on gastronomy tourism in order to create a new market segment for themselves. It is necessary to investigate what exactly is gastronomy and why it is a motivational factor.

\section{GiRiş}

Gastronomi kavramı oldukça köklü geçmişe sahip bir bilim dalını ifade etmesine rağmen gastronomi turizmi, özellikle son on yıldır tartışılan ve farklı bakış açılarıyla yeni çalışmalar kazandırılan bir alan olarak dikkat çekmektedir. Önceki araştırmalar; tanım denemeleri ve araştırma alanları konusunda farklılıklar sergileseler de genel olarak gastronomi turizminin varlı̆̆ 1 ve seyahat motivasyonları arasında yer aldığ 1 ortak noktasında birleşilmektedir. Bununla birlikte gastronomi biliminin turizm amaçlı kullanım koşul ve ölçütleri ile kapsamı konusundaki tartışmalar da devam etmektedir.

Yunanca gastri (mide) ile nomos (yasa, kurallar) (Tez 2012) sözcüklerinden meydana gelen gastronomi kavramı, Fransızcada "yemeği iyi yeme merakı; sağlığa uygun, iyi düzenlenmiş, hoş ve lezzetli mutfak, yemek düzeni ve sistemi" anlamlarına gelmektedir (Larousse Gastronomique 1988'den aktaran Çakır 2009; Can vd. 2012). Ancak bu sınır11 tanımın gastronomi bilimini açıklamada yetersiz kaldığı bilinmektedir. Bununla birlikte gastronomi 
kelimesinin kökeninden daha çok kavramsal anlamını ortaya koymak önemli bir konudur.

Akgöl (2012) araştırmasında, gastronominin insan refahını ve beslenmesini ilgilendiren her alanda sağlanmış detaylı bilgi birikimi olduğundan ve kökeninin Antik Yunanlılara kadar uzandığından bahsetmektedir. Nitekim MS 4. yüzyılda Sicil Yunan Aristokratlarının yiyecek ve şarap rehberi olarak Akdeniz bölgesinin en eski kitabı olan "gastronomia" adlı eserin yayınlanmış olması (Wilkins ve Hill 1994) bu savı destekler niteliktedir. İlgili yazın incelendiğinde gastronomi bilimi ile ilgili detaylı bir diğer çalışmanın Fransız Jean Anthelme Brillat-Savarin (1755-1826) tarafından kaleme alındığı anlaşılmaktadır. Savarin'in 1825 yılında “La Physiologie Dugout" adlı eseri yayınlanmış ve bu eser "Tat Fizyolojisi" olarak İngilizceye çevrilmiştir. Savarin kitabında yemek ve lezzet konularına fizik ve kimya açılarından yaklaşarak yeni bir anlayışın oluşmasına (Savarin 1994'ten aktaran Bahçe vd. 2013) öncülük etmiş ve yiyecek-içecek bilimi ile ilgili sonraki araştırmalara rehber olmuştur. İlerleyen dönemde gastronominin klasik uygarlıkların mutfak kültürü ve kökleri ile ilgilenen bir bilim dalı olduğu (Kivela ve Crotts 2006) anlayışı daha çok kabul görmeye başlamıştır.

Gastronomi kavramının ortaya çıkış tarihine ilişkin ilgili yazında farklı bakış açıları dikkat çekmektedir. Larousse Gastronomique'a göre bu kavramın ilk defa 1801 yılında Joseph Berchoux'un "Gastronomi ya da Tarladan Sofraya İnsan" kitabiyla kullanıldığı ve Fransızca diline yerleşmiş olduğu vurgulanmaktadır. Buna ek olarak Charles Monselet gastronomiyi "bütün şart ve yaşlarda tadılabilen haz" olarak tanımlamış ve bu kavram 1835 yılında Fransız Akademisi tarafından sözlüğe alınarak resmen onaylanmıştır (Larousse Gastronomique 1988; Scarpa 2002; Mil 2009; Göker 2011).

Gastronomi kelimesinin keşfedilmesinden yaklaşık 200 yıl kadar sonra, Yunan yazar Athenee'nin yemekler, içkiler ve geçmiş tarihçiler ile filozofların yaşam stillerine ilişkin geniş çaplı yazılar yazmaya başladığı bilinmektedir. Ancak Yunan ve Roma İmparatorluğu döneminde birçok yazarın aşçılık ve yemekler hakkındaki araştırmaları kaleme almalarına rağmen bunların tam anlamıyla gastronomi niteliği taşımadı ̆̆ı görüşünde birleşilmiştir (Scarpa 2002).
Kivela ve Crotts'un (2005) Hong Kong'ta ve Hashimoto ile Telfer'in (2013) Kanada'da gastronomi turizmi üzerine yaptıkları araştırmalarda bu faaliyetin turistlerin ziyaret nedenleri arasında olduğu, saptanmıştır. Ayrıca, Karim vd. (2010), Horng ve Tsai (2012a), Okumuş vd. (2007) ve Sheldon ve Fox (2007) farklı ülkelerin gastronomi turizmi açısından karşılaştırmalarını yaparak aralarındaki farklılıkları ortaya koymuşlardır. Ulusal yazında da gastronomi turizmi konusunda son on yllda önemli sayıda çalışma ve araştırma dikkat çekmektedir. YÖK Ulusal Tez Merkezinin arama tabanından "yiyecek turizmi-gastronomi" anahtar sözcükleriyle tarama yapıldığında bu alanla ilişkili ilk yüksek lisans tezinin 1987 'de tamamlandığ görülmektedir. 2010-2013 yılları arasında ise bu sayı toplamda 10'a ulaşmıştır.

Bu çalışmada gastronomi kavramına ilişkin ilgili yazında yer alan tanım denemeleri ve tartışmalar ile gastronomi turizmi konusunda yapılan araştırmalara ilişkin genel bir yazın değerlendirmesi sunulmuştur.

\section{GASTRONOMI KAVRAMI}

Farklı bilim dallarıyla olan bağlantısı da dikkate alındığında gastronomi hakkında yapılan tanım denemelerinin sayısal çokluğu şaşırtıcı değildir. Ancak bu bölümde farklı tanım denemelerinden daha çok turizm bağlantılı gastronomi tanımları üzerinde durulmuştur. Gastronomi konusunda ilk dönemlerde "gösteriş için süslü ve kapsamlı yemekler" biçiminde tanım denemesi yapılsa da bu açıklama sonraki dönemlerde yerini farklı ve daha kapsamlı ifadelere bırakmıştır (Barkat ve Vermignon 2006). Örneğin, Scarpato (2000), gastronomi kavramını, yiyeceklerin hazırlanması, üretimi ve genel olarak sunumunun yanı sıra pişirme ve yeme özelliklerini de yansıtan mükemmellikle birlikte sürdürülmesi şeklinde tanımlayarak önceki tanım denemelerine yeni bir boyut kazandırmıştır.

Richards (2002), gastronomiyi yemeğin hazırlanması, pişirilmesi, sunumu ve tüketilmesinin bir yansıması olarak açıklarken Kivela ve Crotts (2006), yemek yeme sanatını inceleyen bir disiplin dalı olarak ifade etmektedir. Gillespie ve Cousins (2001), bu kavramı besinlerden daha fazla nasıl zevk alınacağı ve bu zevkin sınırının nasıl aşılması gerektiğini araştıran bir bilim dalı olarak açılamaktadır. Eren de (2007) içinde barındırdı ̆̆ı tüm 
sanatsal ve bilimsel unsurlarla yiyecek ve içeceklerin tarihsel gelişim sürecinden başlayarak tüm özelliklerin ayrıntılı bir biçimde anlaşılması, uygulanması ve geliştirilerek günümüz şartlarına uyarlanması çalışmalarını kapsayan bir bilim dalı olarak tanımlamaktadır. Hatipoğlu'nun tez çalışmasinda ise gastronomi için "belirli bölge ve ülkelerle ilgili, mutfak gelenek ve göreneklerini de içeren, iyi yiyecek yeme bilim ve sanatı" (Hatipoglu 2010) ifadesi kullanılmıştır. Yenilebilir tüm maddelerin hijyenik olabilen ama sağlığa uygun olması gerekmeyen şekilde, azami damak ve göz zevkini amaçlayarak, yemeye hazır halde sofraya getirilmesine kadar olan süreç, gastronominin alanında yer almaktadır (Baysal ve Küçükarslan 2003). Bununla birlikte, Gillespie ve Cousins (2001), çalışmalarında gastronomiyi tanımlamanın kolay bir iş olmadığından bahsetmektedirler.

Özetle gastronomi bir bilim dalı (Wilkins ve Hill 1994; Santich 2004; Eren 2007) olarak kabul görmektedir. Ancak moleküler gastronominin kurucuları, gastronominin bir bilim dalı olmakla birlikte kesin bir tanımının da olmadığı noktasında birleşmektedirler (Gillespie ve Cousins 2001). Moleküler gastronomi, McGee (2004) tarafından "lezzetli olmanın bilimsel çalışması" ve Pedersen (2008) tarafından "iyi yemek seçme, hazırlama ve yeme sanatı" olarak tanımlanmaktadır. Başlı başına gastronomik değerler; kültürel, coğrafik, toplumsal ve sosyal beslenme faktörleri gibi birçok farklı unsura dayanmaktadır. Gastronomi, özünde fen bilimleri (fizik, kimya ve biyoloji) ve sosyal bilimlerle (ekonomi, sosyoloji, antropoloji, psikoloji, işletmecilik, yönetim, pazarlama vb.) iç içe olup bu iki bilim için zengin bir araştırma alanıdır. Konunun yeme-içme ile ilgili olması beslenme bilimi ile doğrudan ilişkili olarak tadın fizyolojisi ve tat alma, şarap üretimi, besin ögelerinin insan vücudundaki işlevleri, gida maddelerinin seçimindeki niteliklerinin belirlenmesi, besinlerin fiziksel, kimyasal ve biyolojik olarak bozulmalarının önlenmesi için hijyen ve sanitasyon kurallarına uygun üretim süreçlerin geliştirilmesi açısından ise daha çok fen bilimlerine gereksinim duymaktadır (Ilhan 2011; Özçil 2012).

Tüm tanımların ortak özellikleri dikkate alındığında; gastronomiyi "temelinde belirli kültürlerin yansıması olan, yemek hazırlama, pişirme, sunum ve yeme-içme deneyimiyle ilgili bir sanat ve bilim dalı" şeklinde tanımlamak mümkündür. Bilim dalı olması nedeniyle gastronomi, belirli kuralları içer- mektedir. Tanıma ilave edilen "sanat" kavramı da haz ve estetikliğe çağrışım yapmaktadır.

\section{GASTRONOMI TURIZMI}

Gastronomi turizmi kavramı ve ilgili araştırmalar oldukça yenidir. Bu yenilik ülke ve bölgeleri, yeni bir turizm pazarı oluşturma ve turizm gelirlerini arttırma konusunda heveslendirmektedir. Niş pazar hacminde oluşan kitlenin gelecek dönemlerde artması şaşırtıcı değildir. Bununla birlikte gerçek anlamda gastronomi turizminin ne anlama geldiği ve kapsamının iyi bilinmesi gerekmektedir. Genel bir yaklaşımla bu kavramın gelişim sürecini ve yapılan araştırmaları gözden geçirmek yararlı olacaktır. Bu kapsamda öncelikle dünya mutfağındaki gelişmeler aşağıda ele alınmaktadır.

Dünyadaki en ünlü aşçılardan birisi olan Escoffier, sadece kralların, prenslerin ve soyluların aşçısı olarak çalışmamış, aynı zamanda Avrupa'nın en kaliteli otel ve restoranlarını yönetmiştir. Bunlar arasinda; Paris'teki The Place Vendome ile Londra'daki Savoy ve Carlton Oteli popüler olanlarıdır. Escoffier, servis ve mutfak organizasyonunda köklü değişiklikler yapmış, mutfakta uzmanlaşmaya önem verip menüleri sadeleştirerek yemekleri planlı bir düzen üzerine oluşturmuş ve saray mutfağının çok görkemli, abartılı ve oldukça karışık olan menü ögelerini çok sade biçimde hazırlamıştır. Benzer olarak Ortaçağda İtalyanlar tarımdan, tıp bilimine kadar yaşamlarını etkileyen gastronominin tüm boyutlarını kapsamlı bir şekilde ele almişlardır (Scarpa 2002).

Scarpa (2002) çalışmasında, yeme ve içme faaliyetlerini bir toplumun olağan gereksinimleri ile ilgili olmaktan daha çok bu faaliyetlerin verdiği keyif ve mutlulukla ilişkili olduğunu ifade etmiştir. Bununla birlikte Santich (2004) araştırmasında, bir ülkenin veya bölgenin gastronomik karakterinin (üretilen ve tüketilen yiyecek - içeceklerin türü ile ilgili), gastronomik özelliklerinin (bir ülkeye özgü yiyecek - içecekler, bir bölgeye özgü restoran ve yemekler) ve gastronomi turizminin (yiyecek ve içecek üzerine odaklı turizm yapısı, özellikle gastronomik unsurları) birbirleriyle ilişkilendirilse de net bir tanımın ortaya konulmasının zorluğundan bahsetmektedir.

Turizm, konuğu karşılama, onun konforu ve huzuru ile ilgilenme, onu memnun etme ve konaklama, yeme ve içme ile ilgili ihtiyaçlarını karşılamayı ifade etmektedir. Başka bir açıklamayla konakla- 
ma endüstrisinin ana teması kişilerin evlerinden çıtıkları andan itibaren temel ihtiyaçlarını karşılamaları adına yeme, içme, konaklama ve ulaşım hizmetlerini sunmaktır (Brotherton ve Wood 2000; Santich 2004). Bu açıklamaya farklı bir yaklaşım Brotherton (1999) tarafından "yiyecek, içecek ve konaklamanın uyum içinde olduğu bir sistem olarak tasarlanan gönüllü katılımı gerektiren çağdaş bir insan değişimidir" şeklinde getirilmiştir. Brotherton'un tanımı, uygun konaklama davranışlarını ve bu davranışlarına verilen tepkileri içeren ilişki değişimini ifade etmektedir. Özetle, ilgili bölümlerin uyumlu bir beraberlik için çağdaş ve ilerleyen gönüllü insan değişimi çerçevesiyle içecek, yiyecek, konaklama sağlayan ve kendi içinde özgünlük oluşturan ticari organizasyonlar biçiminde tanımlanmaktadır (Brotherton ve Wood 2000). Ev sahibinin görevi yabancıya, yani konuğa farklı bir çevrede konfor sunmak ve konuğunun bulunduğu sürece onun mutluluğundan sorumlu olmaktır (Brilliat-Savarin 1994).

İlgili yazında yeni bir terim olan gastronomi ve turizm kavramları 1983 yılından bu yana birlikte değerlendirilmiş (Belisle 1983; Hobsbawm ve Ranger 1983) ve diğer toplumların kültürlerini yiyecekleri aracılığı ile öğrendiklerini ifade etmek için kullanılmıştır (Wolf 2006; Karim ve Chi 2010; Horng ve Tsai 2012b). Lin vd. (2011) gastronomi turizmini, "yiyecek ve içecekleri tatmak amaciyla seyahat etme ya da en azından seyahatin bir kısmında yiyecek ve içecekleri tatma motivasyonu ile hareket etme" şeklinde yeniden tanımlamıştır. Gastronomi turizmi, yiyecek ve içeceğin turizm endüstrisindeki yeri nedeniyle ekonomik ve toplumsal kalkınmaya büyük katkıda bulunabilecek potansiyele sahip bir turizm (Wolf 2006) çeşidi olarak görülmektedir. Akgöl (2012) ise gastronomi turizmini, "temel motivasyon faktörü özel bir yemek türünü tatmak veya bir yemeğin üretilmesini görmek amacryla, yiyecek üreticilerini, yemek festivallerini, restoranları ve özel alanları ziyaret etmek" biçiminde açıklamaktadır. Hall ve Mitchell (2000) gastronomi turizmini, "birincil ve ikincil yiyecek üreticilerini ve yiyecek festivallerini ziyaret etmek, yiyecekleriyle tanınmış belirli destinasyonlardaki konaklama işletmelerinde ve restoranlarda bu yiyecekleri tatmak ve tanımak amaciyla yapılan seyahatler" olarak tanımlamaktadırlar.

Richards (2002) araştırmasında gastronomi turizmini, turistlerin yemek yapmayı öğrenebilme- leri, içeriğinde kullanılanlar hakkında bilgi sahibi olabilmeleri, bu yolla gelişebilmeleri ve mutfak geleneklerinin içinde nasıl var olunduğuna katılabilmeleri açısından giderek büyüyen yaratıcı bir sektör olarak tanımlamaktadır. Başka bir tanımda ise gastronomi turizmi; "farklı kültürlere özgü yiyecek ve içecekleri yine o kültüre özgü bir şekilde tüketmek için seyahat etmek" (Durlu, Özkaya ve Can 2012) biçiminde ifade edilmektedir. Long (2003) gastronomi turizmini, bilinenden farklı bir mutfak kültüründeki yiyeceklerin tüketilmesini, hazırlanmasını, sunulmasını ve mutfağını, ögün sistemlerini ve yemek yeme biçimlerini keşfetmek amaciyla gerçekleştirilen turizm çeşidi olarak açıklamaktadır. Yeme-içme etkinliklerinin, bir toplumun kültürünü öğrenmede en önemli araçlardan biri olduğu araştırmacılar tarafından belirtilmektedir (Yüncü 2009).

Yukarıda yapılan tanımlar içinde dikkat çeken ve kişileri seyahate iten üç temel unsur bulunmaktadır. Bu unsarlar aşağıdaki gibi sıralanabilir:

- Farklı yiyecek-içecekleri tatma ve üretim sürecini görme,

- Değişik kültürleri mutfak geleneklerini bizzat gözlemleyerek öğrenme,

- Yeni öğün sistemleri ve yeme stillerini keşfetme.

Bu unsurların yer aldığı yeni bir tanım denemesi yapmak mümkündür. Gastronomi turizmi, kişilerin farklı yiyecek-içecekleri tatma, üretim sürecini görme, değişik kültürleri mutfak geleneklerini inceleyerek öğrenme, yeni öğün sistemleri ve yeme stillerini keşfetme gibi istekleri doğrultusunda gerçekleştirilen, seyahat ve konaklamayı da kapsayan bir ilişkiler bütünüdür ve yapılacak olan seyahatin hedefinde; bir bölge, bir yiyecek-içecek işletmesi ya da bir festival olabileceği gibi daha özele indirgenerek bir şefin yemekleri de bulunabilmektedir. Özetle gastronomi turizmi insanların yiyecekler ve bu yiyeceklerle ilgili deneyimlerini tanımlayan bir kavramdır (Karim ve Chi 2010).

\section{GASTRONOMI TURIZMINE ILIŞKIN MEVCUT LITERATÜR}

Gastronomi turizminin yeni bir kavram olması, ilgili araştırma sayısında özellikle son on yılda önemli bir artışa zemin hazırlamıştır. İlgili yazında gastronomi turizmi konusunda toplam 82 çalışmaya ulaşılmış ve bu çalışmalar Tablo 1'de sunulmuştur. 


\begin{tabular}{|c|c|c|c|}
\hline \multicolumn{4}{|c|}{ MAKALE } \\
\hline Yazar & Çalışmanın Orijinal Başlığı & Yayın Yeri & $Y_{I} l$ \\
\hline Hillel vd. & $\begin{array}{l}\text { What Makes Gastronomic Destination } \\
\text { Attractive? Evidence From The Israeli Negev }\end{array}$ & Tourism Management & 2013 \\
\hline Kumar & $\begin{array}{l}\text { Gastronomy Tourism Potential: A Case Study Of } \\
\text { Northern India }\end{array}$ & $\begin{array}{l}\text { International Journal of } \\
\text { Rewievs, Surveys and } \\
\text { Research }\end{array}$ & 2013 \\
\hline $\begin{array}{l}\text { Hjalager ve } \\
\text { Johansen }\end{array}$ & $\begin{array}{l}\text { Food Tourism in Protected Areas- Sustainability } \\
\text { for producers, the environment and tourism? }\end{array}$ & $\begin{array}{c}\text { Journal of Sustainable } \\
\text { Tourism }\end{array}$ & 2013 \\
\hline Deveci vd. & $\begin{array}{l}\text { Kırsal Turizm İle Gastronomi Turizmi İlişkisi: } \\
\text { Bigadiç Örneği }\end{array}$ & $\begin{array}{c}\text { Uluslararası Sosyal ve } \\
\text { Ekonomik Bilimler Dergisi }\end{array}$ & 2013 \\
\hline $\begin{array}{l}\text { Canizares } \\
\text { ve Guzman }\end{array}$ & $\begin{array}{l}\text { Gastronomy As A Tourism Resource: Profile Of } \\
\text { The Culinary Tourist }\end{array}$ & Current Issues in Tourism & 2012 \\
\hline $\begin{array}{l}\text { Lakıcevic } \\
\text { vd. }\end{array}$ & Gastronomic Festivals In Rural Regions of Serbia & Megatrend Review & 2012 \\
\hline $\begin{array}{l}\text { Horng ve } \\
\text { Tsai }\end{array}$ & $\begin{array}{l}\text { Culinary Tourism Strategic Development: An } \\
\text { Asia-Pacific Perspective }\end{array}$ & $\begin{array}{l}\text { International Journal Of } \\
\text { Tourism Research }\end{array}$ & $2012 a$ \\
\hline Hussain vd. & $\begin{array}{l}\text { Enhancing The Cultural Tourism Experience } \\
\text { Through Gastronomy in the Maltives }\end{array}$ & $\begin{array}{c}\text { Journal of Tourism } \\
\text { Challenges and Trends }\end{array}$ & 2012 \\
\hline $\begin{array}{l}\text { Chaney ve } \\
\text { Ryan }\end{array}$ & $\begin{array}{l}\text { Analyzing The Evolution of Singapore's World } \\
\text { Gourmet Summit: An Example of } \\
\text { Gastronomic Tourism }\end{array}$ & $\begin{array}{l}\text { International Journal of } \\
\text { Hospitality Management }\end{array}$ & 2012 \\
\hline $\begin{array}{l}\text { Durlu } \\
\text { Özkaya ve } \\
\text { Can }\end{array}$ & $\begin{array}{l}\text { Gastronomi Turizminin } \\
\text { Pazarlamasına Etkisi }\end{array}$ & Türktarım Dergisi & 2012 \\
\hline $\begin{array}{l}\text { Hjalager ve } \\
\text { Johansen }\end{array}$ & $\begin{array}{l}\text { Food Tourism In Protected Areas - } \\
\text { Sustainability For Producers, The } \\
\text { Environment And Tourism? }\end{array}$ & $\begin{array}{l}\text { Journal of Sustainable } \\
\text { Tourism }\end{array}$ & 2012 \\
\hline $\begin{array}{l}\text { Horng ve } \\
\text { Tsai }\end{array}$ & $\begin{array}{l}\text { Exploring Marketing Strategies for Culinary } \\
\text { Tourism in Hong Kong and Singapore }\end{array}$ & $\begin{array}{l}\text { Asia Pacific Journal of } \\
\text { Tourism Research }\end{array}$ & $2012 b$ \\
\hline $\begin{array}{l}\text { Giampiccoli } \\
\text { ve Kalis }\end{array}$ & $\begin{array}{l}\text { Tourism, Food, and Culture: Community-Based } \\
\text { Tourism, Local Food, and Community } \\
\text { Development in Mpondoland }\end{array}$ & $\begin{array}{l}\text { Culture, Agriculture, Food } \\
\text { and Environment }\end{array}$ & 2012 \\
\hline Kesici & $\begin{array}{l}\text { Kırsal Turizme Olan Talepte Yöresel Yiyecek ve } \\
\text { İçecek Kültürünün Rolü }\end{array}$ & $\begin{array}{l}\text { KMÜ Sosyal ve Ekonomik } \\
\text { Araştırmalar Dergisi }\end{array}$ & 2012 \\
\hline Yurtseven & $\begin{array}{l}\text { Sustainable Gastronomic Tourism in Gokceada } \\
\text { (Imbros): Local and Authentic Perspectives }\end{array}$ & $\begin{array}{l}\text { International Journal of } \\
\text { Humanities and Social } \\
\text { Science }\end{array}$ & 2011 \\
\hline Blakey & $\begin{array}{l}\text { Consuming Place: Tourism's } \\
\text { Gastronomy Connection }\end{array}$ & $\begin{array}{l}\text { Hawai'i Community } \\
\text { College }\end{array}$ & 2011 \\
\hline $\begin{array}{l}\text { Guzmán \& } \\
\text { Cañizares }\end{array}$ & $\begin{array}{l}\text { Gastronomy, Tourism and Destination } \\
\text { Differentiation: A Case Study in Spain }\end{array}$ & $\begin{array}{l}\text { Academic Research Centre } \\
\text { of Canada }\end{array}$ & 2011 \\
\hline Nilssona vd. & $\begin{array}{l}\text { 'Citta'Slow' Eco-Gastronomic Heritage as a Tool } \\
\text { For Destination Development }\end{array}$ & Current Issues in Tourism & 2011 \\
\hline
\end{tabular}


Tablo 1. Gastronomi Turizmiyle İlgili Yazın Künyeleri (Makalelel, Devam)

\begin{tabular}{|c|c|c|c|}
\hline \multicolumn{4}{|c|}{ MAKALE } \\
\hline Yazar & Çalışmanın Orijinal Başlığı & Yayın Yeri & $Y_{l} l$ \\
\hline $\begin{array}{l}\text { Harrington ve } \\
\text { Ottenbacher }\end{array}$ & $\begin{array}{l}\text { Culinary Tourism: A Case Study of the } \\
\text { Gastronomic Capital }\end{array}$ & $\begin{array}{l}\text { Journal of Culinary Science } \\
\text { \& Technology }\end{array}$ & 2010 \\
\hline Karim ve Chi & $\begin{array}{l}\text { Culinary Tourism As A Destination Attraction: } \\
\text { An Empiricial Examination Of Destinations Food } \\
\text { Image }\end{array}$ & $\begin{array}{c}\text { Journal Of Hospitality } \\
\text { Marketing \& Management }\end{array}$ & 2010 \\
\hline Sims & $\begin{array}{l}\text { Food, Place And Authenticity: Local Food and } \\
\text { The Sustainable Tourism Experience }\end{array}$ & $\begin{array}{c}\text { Journal of Sustainable } \\
\text { Tourism }\end{array}$ & 2009 \\
\hline Henderson & Food Tourism Reviewed & British Food Journal & 2009 \\
\hline Smith ve Xiao & $\begin{array}{l}\text { Culinary Tourism Supply Chains: A Preliminary } \\
\text { Examination }\end{array}$ & Journal of Travel Research & 2008 \\
\hline Correia vd. & $\begin{array}{l}\text { The Determinants Of Gastronomic Tourists' } \\
\text { Satisfaction: A Second- Order Factor Analysis }\end{array}$ & Journal of Food Service & 2008 \\
\hline Correia vd. & $\begin{array}{l}\text { The Determinants Of Gastronomic Tourists' } \\
\text { Satisfaction: A Second- Order Factor Analysis }\end{array}$ & Journal of Food Service & 2008 \\
\hline Fox & $\begin{array}{l}\text { Reinventing The Gastronomic Identity Of } \\
\text { Croatian Tourist Destinations }\end{array}$ & $\begin{array}{l}\text { International Journal of } \\
\text { Hospitality Management }\end{array}$ & 2007 \\
\hline Correia vd. & $\begin{array}{l}\text { Modeling Motivations and Perceptions Of } \\
\text { Portuguese Tourists. }\end{array}$ & $\begin{array}{l}\text { Journal of Business } \\
\text { Research }\end{array}$ & 2007 \\
\hline Kim vd. & $\begin{array}{l}\text { Building a Model Of Local Food Consumption On } \\
\text { Trips And Holidays: A Grounded Theory } \\
\text { Approach }\end{array}$ & $\begin{array}{l}\text { International Journal of } \\
\text { HospitalityManagement }\end{array}$ & 2007 \\
\hline Molz & $\begin{array}{l}\text { Eating Difference: The Cosmopolitan Motilities } \\
\text { of Culinary Tourism }\end{array}$ & Space And Culture & 2007 \\
\hline Okumus vd. & $\begin{array}{l}\text { Incorporating Local And International Cuisines } \\
\text { In The Marketing Of Tourism Destinations: The } \\
\text { Cases of Hong Kong and Turkey }\end{array}$ & Tourism Management & 2007 \\
\hline Westering & $\begin{array}{l}\text { Heritage and Gastronomy: } \\
\text { The Pursuits of the 'New Tourist' }\end{array}$ & $\begin{array}{l}\text { International } \\
\text { Journal of Heritage } \\
\text { Studies }\end{array}$ & 2007 \\
\hline $\begin{array}{l}\text { Kivela ve } \\
\text { Crotts }\end{array}$ & $\begin{array}{l}\text { Tourism and Gastronomy: Gastronomy's } \\
\text { Influence On How Tourists Experience A } \\
\text { Destination }\end{array}$ & $\begin{array}{l}\text { Journal of Hospitality and } \\
\text { Tourism Research }\end{array}$ & 2006 \\
\hline $\begin{array}{l}\text { Hashimoto ve } \\
\text { Telfer }\end{array}$ & $\begin{array}{l}\text { Selling Canadian Culinary Tourism: Branding The } \\
\text { Global And The Regional Product }\end{array}$ & $\begin{array}{l}\text { Tourism Geographies: An } \\
\text { International Journal of } \\
\text { Tourism Space, Place and } \\
\text { Environment }\end{array}$ & 2006 \\
\hline $\begin{array}{l}\text { Ignatov \& } \\
\text { Smith }\end{array}$ & Segmenting Canadian Culinary Tourists & Current Issues in Tourism & 2006 \\
\hline Hall & $\begin{array}{l}\text { Culinary Tourism and Regional Development: } \\
\text { From Slow Food To Slow Tourism? }\end{array}$ & Current Issues in Tourism & 2006 \\
\hline $\begin{array}{l}\text { Kivela } \\
\text { veCrotts }\end{array}$ & $\begin{array}{l}\text { Gastronomy Tourism: } \\
\text { A Meaningful Travel Market Segment }\end{array}$ & $\begin{array}{c}\text { Journal of Culinary Science } \\
\text { \& Technology }\end{array}$ & 2005 \\
\hline
\end{tabular}




\begin{tabular}{|c|c|c|c|}
\hline \multicolumn{4}{|c|}{ MAKALE } \\
\hline Yazar & Çalışmanın Orijinal Başlığı & Yayın Yeri & Yıl \\
\hline Ganter & $\begin{array}{l}\text { Changes In Work Organizations In French Top- } \\
\text { Quality Restaurants }\end{array}$ & Business History & 2004 \\
\hline $\begin{array}{l}\text { Alant ve } \\
\text { Bruwer }\end{array}$ & $\begin{array}{l}\text { Wine Tourism Behavior In The Context Of A } \\
\text { Motivational Framework For Wine Regions and } \\
\text { Cellar Doors }\end{array}$ & Journal of Wine Research & 2004 \\
\hline Josiam vd. & $\begin{array}{l}\text { The Historount: Heritage Tourism At Mickey's } \\
\text { Dining Car }\end{array}$ & Tourism Management & 2004 \\
\hline Santich & $\begin{array}{l}\text { The Study of Gastronomy and Its Relevance To } \\
\text { Hospitality Education and Training }\end{array}$ & Hospitality Management & 2004 \\
\hline $\begin{array}{l}\text { Quan ve } \\
\text { Wang }\end{array}$ & $\begin{array}{l}\text { Towards A Structural Model Of The Tourist } \\
\text { Experience: An illustration From Food } \\
\text { Experiences In Tourism }\end{array}$ & Tourism Management & 2004 \\
\hline Torres & $\begin{array}{l}\text { Linkages Between Tourism and Agriculture in } \\
\text { Mexico. }\end{array}$ & $\begin{array}{l}\text { Annals of Tourism } \\
\text { Research }\end{array}$ & 2003 \\
\hline Scarpato & $\begin{array}{l}\text { Gastronomy As A Tourist Product: The } \\
\text { Perspectives Of Gastronomy Studies. In A-M } \\
\text { Hjalager and G. Richards (eds.) }\end{array}$ & Tourism Gastronomy & 2002 \\
\hline Au ve Law & Categorical Classification of Tourism Dining & $\begin{array}{l}\text { Annals of Tourism } \\
\text { Research }\end{array}$ & 2002 \\
\hline Williams & $\begin{array}{l}\text { The Evolving Images of Wine Tourism } \\
\text { Destinations }\end{array}$ & $\begin{array}{l}\text { Tourism Recreation } \\
\text { Research }\end{array}$ & 2001 \\
\hline $\begin{array}{l}\text { Hjalager } \\
\text { veCorigliano }\end{array}$ & Food For Tourists Determinants of An Image & $\begin{array}{l}\text { International Journal Of } \\
\text { Tourism Research }\end{array}$ & 2000 \\
\hline Nield vd. & The Role of Food Service in Tourist Satisfaction & Hospitality Management & 2000 \\
\hline $\begin{array}{l}\text { Charters } \\
\text { veAli-Knight }\end{array}$ & Who is The Wine Tourist? & Tourism Management & 2000 \\
\hline $\begin{array}{l}\text { Hjalager ve } \\
\text { Corigliano }\end{array}$ & Food For Tourists Determinants Of An Image & $\begin{array}{l}\text { International Journal Of } \\
\text { Tourism Research }\end{array}$ & 2000 \\
\hline Telfer ve Wall & Linkages Between Tourism and Food Production & $\begin{array}{l}\text { Annals of Tourism } \\
\text { Research }\end{array}$ & 1996 \\
\hline Reynolds & Culinary Heritage in The Face Of Tourism & $\begin{array}{c}\text { Progress in Tourism } \\
\text { Recreation and Hospitality } \\
\text { Management }\end{array}$ & 1993 \\
\hline $\begin{array}{l}\text { Sheldon ve } \\
\text { Fox }\end{array}$ & $\begin{array}{l}\text { The Role Of Foodservice in Vacation Choice and } \\
\text { Experience: A Cross-Cultural Analysis }\end{array}$ & Journal of Travel Research & 1988 \\
\hline Marris & Does Food Matter? & Tourism Review & 1986 \\
\hline Belisle & Tourism and Food Production in the Caribbean & $\begin{array}{l}\text { Annals of Tourism } \\
\text { Research }\end{array}$ & 1983 \\
\hline
\end{tabular}




\begin{tabular}{|c|c|c|c|}
\hline \multicolumn{4}{|c|}{ BILDIRI } \\
\hline Colovic vd. & $\begin{array}{l}\text { Strategic Networking Improving Gastronomy In } \\
\text { Small Medium Hospitality Enterprises }\end{array}$ & $\begin{array}{l}\text { Tourism \& Hospitalıty } \\
\text { Management Conference } \\
\text { Proceedings }\end{array}$ & 2012 \\
\hline \multirow{2}{*}{$\begin{array}{l}\text { Çevik \& } \\
\text { Saçılık }\end{array}$} & Destinasyonun Rekabet Avantajı Elde & \multirow[b]{2}{*}{ 12. Ulusal Turizm Kongresi } & \multirow[b]{2}{*}{2011} \\
\hline & $\begin{array}{l}\text { Etmesinde Gastronomi Turizminin Rolü: Erdek } \\
\text { Örneği }\end{array}$ & & \\
\hline Sürenkök vd. & $\begin{array}{l}\text { Gastronomy and Tourism in Turkey: } \\
\text { The Role ofICTs }\end{array}$ & $\begin{array}{l}\text { Proceedings of the } \\
\text { International Conference }\end{array}$ & 2010 \\
\hline Barrere vd. & $\begin{array}{l}\text { Luxury Gastronomy as an Attractive Activity for } \\
\text { Luxury Tourism }\end{array}$ & CEnometrie XVI & 2009 \\
\hline Küçükaltan & $\begin{array}{l}\text { Küreselleşme Sürecinde Gastronomide Yöresel } \\
\text { Tatların Turistlerin Destinasyon Tercihlerine ve } \\
\text { Ülke Ekonomilerine Etkileri }\end{array}$ & $\begin{array}{l}\text { 3. Ulusal Gastronomi } \\
\text { Sempozyumu }\end{array}$ & 2009 \\
\hline Yüncü & $\begin{array}{l}\text { Sürdürülebilir Turizm Açısından Gastronomi } \\
\text { Turizmi ve Perşembe Yaylası }\end{array}$ & $\begin{array}{l}\text { 10. Aybastı-Kabataş } \\
\text { Kurultayı }\end{array}$ & 2010 \\
\hline $\begin{array}{l}\text { Barkat ve } \\
\text { Vermignon }\end{array}$ & $\begin{array}{l}\text { Gastronomy Tourism: A Comparative Study of } \\
\text { two French Regions: Brittany and La Martinique }\end{array}$ & $\begin{array}{l}\text { Sustainable Tourism wit } \\
\text { special Reference to } \\
\text { Islands and Small States } \\
\text { Conference }\end{array}$ & 2006 \\
\hline
\end{tabular}

Tablo 1. Gastronomi Turizmiyle İlgili Yazın Künyeleri (Kitaplar)

\begin{tabular}{|c|c|c|c|}
\hline \multicolumn{4}{|c|}{ KITAP } \\
\hline $\begin{array}{l}\text { Blichfeldt } \\
\text { veTherkelsen }\end{array}$ & $\begin{array}{l}\text { Food and Tourism: } \\
\text { Michelin, Moussaka and McDonald's }\end{array}$ & $\begin{array}{c}\text { TRU \& Department of } \\
\text { Culture and Global Studies } \\
\text { Aalborg University }\end{array}$ & 2010 \\
\hline Cheung & $\begin{array}{l}\text { Gastronomy And Tourism: A Case Study of } \\
\text { Gourmet Country-Style Cuisine in Hong Kong }\end{array}$ & $\begin{array}{l}\text { Asia on Tour: Exploring } \\
\text { the rise of Asian tourism }\end{array}$ & 2008 \\
\hline Long & Culinary Tourism & $\begin{array}{l}\text { The University Press Of } \\
\text { Kentucky }\end{array}$ & 2005 \\
\hline Boniface & Tasting Tourism: Traveling For Food and Drink & $\begin{array}{c}\text { Ashgate Publishing } \\
\text { Limited }\end{array}$ & 2003 \\
\hline Boyne vd. & Wine, Food, and Tourism Marketing & $\begin{array}{l}\text { The Harworth Hospitality } \\
\text { Press }\end{array}$ & 2003 \\
\hline $\begin{array}{l}\text { Macionis ve } \\
\text { Cambourne }\end{array}$ & Food Tourism Around The World & Butterworth Heinemann & 2002 \\
\hline Bratec & $\begin{array}{l}\text { Sustaining through Gastronomy: The Case of } \\
\text { Slow Food Movement in Slovenia, its Impacts on } \\
\text { Socio-Cultural Environments and Tourism } \\
\text { Development }\end{array}$ & $\begin{array}{l}\text { Sustaining Quality of Life } \\
\text { through Tourism- }\end{array}$ & 2012 \\
\hline
\end{tabular}


TEZ

\begin{tabular}{|c|c|c|c|}
\hline Soner & $\begin{array}{l}\text { Gastronomy Tourism: A Solution For Small Cities } \\
\text { Marketing and Regional Development }\end{array}$ & Yeditepe Üniversitesi & 2013 \\
\hline Akgöl & $\begin{array}{l}\text { Gastronomi Turizmi ve Türkiye'yi Ziyaret Eden } \\
\text { Yabancı Turistlerin Gastronomi Deneyimlerinin } \\
\text { Değerlendirilmesi }\end{array}$ & Mersin Üniversitesi & 2012 \\
\hline Çağlı & $\begin{array}{l}\text { Türkiye'de Yerel Kültürün Turizm Odaklı } \\
\text { Kalkınmadaki Rolü: Gastronomi Turizmi Örneği }\end{array}$ & İstanbul Üniversitesi & 2012 \\
\hline Göker & $\begin{array}{l}\text { Destinasyon Çekicilik Unsuru Olarak Gastronomi } \\
\text { Turizmi (Balıkesir İli Örneği) }\end{array}$ & Balıkesir Üniversitesi & 2011 \\
\hline Göynüşen & $\begin{array}{l}\text { Edirne'deki Gastronomik Kültürün Kentin } \\
\text { Pazarlama ve Markalaşmasına Etkileri }\end{array}$ & Trakya Üniversitesi & 2011 \\
\hline Dilsiz & $\begin{array}{l}\text { Türkiye'de Gastronomi ve Turizm } \\
\text { (İstanbul Örneği) }\end{array}$ & İstanbul Üniversitesi & 2010 \\
\hline Hatipoğlu & 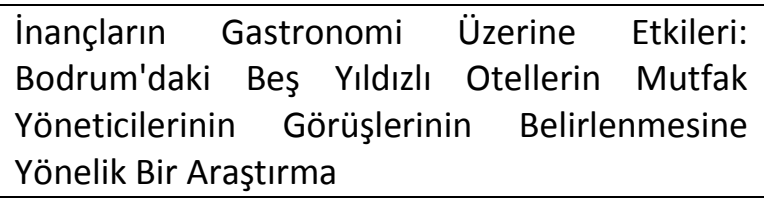 & Sakarya Üniversitesi & 2010 \\
\hline Hamamcıbaşı & $\begin{array}{l}\text { Yiyecek Turizmi ve Yiyecek Turizmi Açısından } \\
\text { Bozcaada'nın Kaynakları }\end{array}$ & $\begin{array}{l}\text { Çanakkale Onsekiz Mart } \\
\text { Üniversitesi }\end{array}$ & 2006 \\
\hline Hacısüleyman & $\begin{array}{l}\text { Otelcilik ve Gastronomi Alanında iş } \\
\text { Organizasyonu ve Yönetimi }\end{array}$ & İstanbul Üniversitesi & 1987 \\
\hline
\end{tabular}

$\mathrm{Bu}$ çalışmaların yayın yılları esas alınarak yapılan değerlendirmeye göre gastronomi turizmi ile ilgili çalışmaların özellikle 1987 yılından bu yana ele alındığı ancak son üç yılda bu alana olan ilginin arttığ1 görülmektedir. Son on yılda yapılan araştırmaların yaklaşık \%40’1 2011-2013 yılları arasında gerçekleşmiştir. 2012 yılına ilişkin araştırmaların önceki yıla oranla yüzde yüz artış göstermesi ise gastronomi turizminin gelecek dönemde araştırmacıların daha fazla dikkatini çekeceği şeklinde yorumlanabilir. 2013 yılına ait yayın sayısının düşük olması ise çalışmaların henüz ulaşılabilir hale gelmemesinden kaynaklandığını akla getirmektedir. Bu nedenle konuya olan eğilimin son durum değerlendirmesinde 2012 yılı temel alınmıştır.

Grafik 1'de gastronomi turizmi ile ilişkilendirilen konu başlıkları sunulmuştur. Grafiğe göre mevcut araştırmaların önemli bir kısmının bölgesel alanlardaki gastronominin turizm içerisinde etkinliğini ve pazarlama açısından önemini ortaya koyduğu görülmektedir (Hobsbawn ve Ranger 1983; Belisle 1983; Marris 1986; Reynolds 1993; Telfer ve Wall 1996; Sheldon ve Fox 1998; Chartes ve Ali-Knight, 2000; Henderson 2000; Hjalager ve Corigliano 2000; Nield vd. 2000; Torres 2001; Williams 2001; $\mathrm{Au}$ ve Law 2002; Boyne vd. 2002; Macionis ve Cambourne 2002; Quan ve Wang 2004; Kivela ve Crotts 2005; Barkat ve Vermignon 2006; Hashimoto ve Telfer 2006; Ignatov ve Smith 2006; Okumus vd. 2007; Correia vd. 2008; Karim ve Chi 2010; Ismailov vd. 2010; Blakey 2011; Hjalager ve Johensen 2012; Lak1cevic vd. 2012; Horng ve Tsai 2012a; Colovic vd. 2012; Bratec 2012; Hussain vd. 2012; Durlu, Özkaya ve Can 2012; Horng ve Tsai 2012b; Giampiccoli ve Kalis 2012; Soner 2013).

Ulaşılabilen çalışmaların \%22'si destinasyon imajı ve gastronominin bu imaj üzerindeki etkilerini belirlemeye yönelirken (Çevik ve Saçılık 2001; Cohen ve Avieli 2004; Ganter 2004; Hall 2006; Karim 2006; Kim vd. 2007; Correia vd. 2007; Fox 2007; 


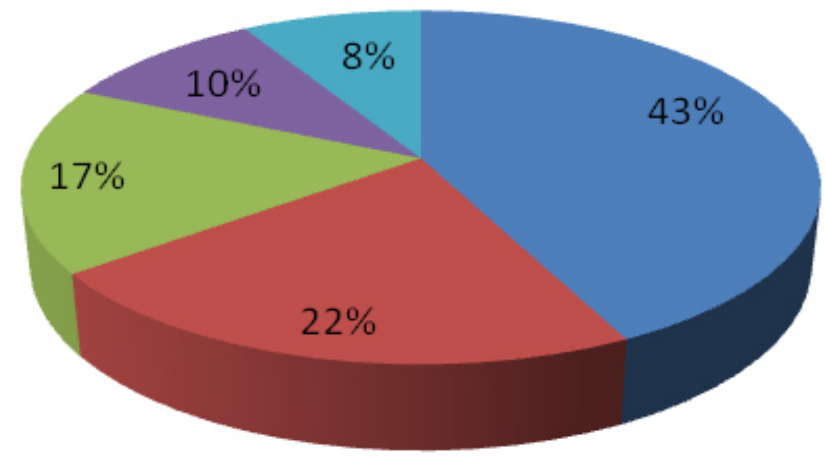

bölgesel alan ve pazarlama

destinasy on imaj1

gastronomi \& kültür ilişkisi

- sey ahatçilerin beklenti ve özellikleri

- gastronomi \& turizm iliş̧kisi

Grafik 1. Gastronomi Turizmine İlişkin Çalışma Konuları

Küçükaltan 2009; Londono 2009; Harrington ve Ottenbacher 2010; Göker 2011; Guzman ve Canizares 2011; Nilssona vd. 2011;Canizares ve Guzman 2012; Hillel vd. 2012; Hillel vd. 2013; Kumar 2013) \%17'si gastronomi ve kültür ilişkisini (Bessiere 1998; Hjalager ve Crigliano 2000; Long 2005; Westering 2007; Cheung 2008; Sims 2009; Yüncü 2010; Göynüşen 2011; Yurtseven 2011; Çağl1 2012; Hjalager ve Johansen 2012; Kesici 2012; Deveci vd. 2013) ele almaktadır. Gastronomi amaçlı seyahat edenlerin özellikleri ve beklentileri (\%10); (Boniface 2003; Alant ve Bruwer 2004; Josiam vd. 2004; Shenoy 2005; Smith ve Xiao 2008; Correia vd. 2008; Barrere 2009; Chaney ve Ryan 2012) gastronomi ve turizm ilişkisi de (\%8); (Scarpato 2002; Santich 2004; Kivela ve Crotts 2006; Molz 2007; Dilsiz 2010; Sürenkök vd. 2010; Blichfeldt ve Therkelsen 2010) üzerinde durulan konular arasındadir.

Gastronomi, turizmde önemli bir motivasyon nedeni (Wolf 2006) ve ziyareti güdüleyen bir unsur olarak dikkat çekmektedir (Akgöl 2012). Hall ve Sharples (2003) ne tür ziyaretlerin gastronomi turizm faaliyetleri arasında yer alacağına ilişkin gerekçeleri şöyle açıklamaktadır:

- Özel nitelikli bir yiyeceği tüketme isteği,

- Belli bir yöreye ait bir ürünü tüketme isteği ve

- Belirli bir aşçının hazırladığı bir yemeği tatma isteğidir.
Gastronomi "yaşama sanatı" olarak, yiyecek - içecek bilgi ve becerilerini kavrama ve yeme içmeden zevk alma, deneyim sağlama boyutları ile algılanmaktadır. Konaklama endüstrisi bu tür deneyimlerin geniş bir alanı durumundadır (Santich 2004). Bununla birlikte özel bir yemeği tatmak, yemeklerin farklı üretim süreçlerini görmek veya ünlü bir şefin elinden hazırlanan yemekleri deneyimlemek, yine bu kapsamda ele alınmaktadır (herhangi bir restorana yapılan günlük olağan ziyaretler gastronomi turizmi kapsamına girmemektedir) (Hall vd. 2003). Yiyecek kültürü, tüketicilerin kutlama etkinlikleri üzerinde önemli rol oynamakta sosyalleşmeyi, eğlenceyi ve deneyimi içermekte ve yeni kültürler ile mutfakları deneme avantajını sunabilmektedir (Mitchel ve Hall 2003).

1980'lere kadar gastronomi sadece Fransa'da üçbeş yıldızlı otellerde yemek yemeyi açıklayan bir kavram olarak bilinirken son yıllarda, kültürel turizmin bir alt bölümlendirmesi olan, diğer kültürlerin içine katılma ve insanlar ile onların kimlikleri konusunda keşfe çıkma faaliyetlerini de kapsamına almaya başlamıştır (Santich 2004). Bu açıdan gastronomi ve turizm arasındaki ilişkiyi bazı yazarlar kültürel turizm içinde değerlendirmektedir (Hjalager ve Corigliano 2000). Zira kültür, gastronomi turizminin gözardı edilemez önemli bir parçasıdır (Du Rand ve Heath 2006).

Birçok araştırma; yemeklerin, şarabın ve yemek yemenin verdiği keyif ve memnuniyet duygusu- 
nun turist deneyimlerinde anahtar rol oynadığını ortaya koymuştur (Hall ve Sharples 2003; Kivela ve Crotts 2006; Correia 2007; Gross vd. 2008). Turizm ürününün bütünleşmiş bir parçası ve değerli bir kısmını oluşturan gastronomi turizminin son yıllarda değişen yüzüne rağmen bir takım kısıtları mevcuttur. Bunun temel sebebi ise bazı turistlerin yerel yiyeceklerden yeterli derecede etkilenmemiş olmaları olarak gösterilmektedir (Cohen ve Avieli 2004). Bununla birlikte gastronomi bazı destinasyonlar için rekabet avantajı sağlayarak ilgili turizm bölümlerini harekete geçirmektedir. Quan ve Wang (2004), turistlerin yiyecek tüketimlerinin en çok hangi odak noktalarından oluştuğunu belirlemek amacıyla gerçekleştirdikleri araştırmalarında turistlerin seyahatlerinde yiyeceğin,

- ana çekici unsur olarak;

- ikincil ya da destek unsur olarak veya

- günlük rutinin bir parçası olarak tercih edilip tüketilmekte olduğunu saptamışlardır.

Birinci ve ikinci unsurlar gastronomi turizminin temel yapısını oluştururken son unsur yiyecek tüketiminin zorunlu olarak yapıldığ 1 bir turizm faaliyeti olarak açıklanmaktadır. Birçok ülke ve bölge, turizm plan ve politikalarında yemeklerin beğenilirliğinin ve buna bağlı olarak seyahatlerin artmasına paralel şekilde yemek ve turizm arasındaki ilişkiyi bir turist çekiciliği olarak dikkate almaya başlamışlardır (Bessire 1998; Wood 2001; Hall 2003; Joppe 2003; Cohen ve Aveili 2004). Turistler için, beslenme ihtiyacının memnuniyeti bir bakıma gastronomik deneyimi oluşturmaktadır. Yemeklerin imajı kültürel kimliklerinin pazarlanması şeklinde turizm destinasyonları için kullanılmakta (Law vd. 2004) ve destinasyonlarının sürdürülebilirliği için özgün bir potansiyel meydana getirmektedir (Du Rand 2003). Bununla birlikte araştırmalarda yemek ve içki turizminin önemi üzerinde de durulmaktadır (Hall ve Macionis 1998; Wolf 2006). Son yıllarda yapılan araştırmalarda gastronomi turizminin günümüzün en hızlı gelişen niş seyahat pazarı olduğu belirtilmektedir (Billups 2007). Nitekim bir bölgenin özgün yemekleri, o bölgenin tercih edilmesinde ve o bölgedeki turistlerin yaşadığ 1 deneyim üzerinde önemli etkiye sahiptir (Mc Kercher vd. 2008).

Gastronomi, turistik destinasyonların pazarlamasında da önemli rol oynamaktadır (Kivela ve
Crotts 2005). Bu bakımdan gastronomi turizmi stratejisi oluşturulurken yerel topluluklar, üretici ve ilgili diğer kuruluşları içeren ortak bir vizyon gerekmektedir (Barkat ve Vermignon 2006).

Yapılan bir araştırmada, sunulan yemeklerin, kişilerin gittikleri yerde kaldıkları otelden memnun ayrilıp ayrilmamaları konusunda anahtar rol oynadığı saptanmıştır (Dilsiz 2010). Correia vd. de (2008) çalışmalarında turist memnuniyetinin ölçülmesinde en önemli belirleyicinin gastronomi olduğunu, fiyat, kalite ve atmosferin ise bundan sonra geldiğini vurgulamaktadır.

Konuyla ilgili yazın incelendiğinde, turistlerin destinasyona seyahat kararlarında ve destinasyonların sadık müşteri kazanmalarında gastronomik değerlerin çok önemli bir rol oynadığını konu alan birçok araştırmaya rastlanmaktadır (Kivela ve Crotts 2005-2006; Du Rand ve Heath 2006; Fox 2007; Karim ve Chi 2010; Harrington ve Ottenbacher 2010; Lin vd. 2011).

Seyahat Endüstrisi Birliği gastronomi turistlerinin \%70'inin gittikleri yerlerde, bölgesel yiyecekler, yemek tarifleri, şarap vb. ürünleri satın alarak yaşadıkları yerlere götürdüklerini, bunları arkadaşları ve aileleri ile paylaşmak istediklerini belirtmektedir (Marzella 2008'den aktaran Kesici 2012). Ling vd. (2010) Malezya'nın yiyecek imajı ile turist memnuniyeti ve gelecekteki davranışları arasındaki ilişkiyi mercek altına aldıkları çalışmada, 392 turiste uyguladıkları anket sonucunca Malezya'nın makul fiyatlardaki kültürel gıda çeşitliliğinin turistlerin memnuniyeti ve tekrar buraya gelmek istedikleri noktasında doğrudan bir etkisi olduğunu belirlemişlerdir.

Quan ve Wang (2004), araştırmalarında; gida şenliklerinin (karnavallarının) ve gastronomi turizminin, turizm destinasyonları için bir kimlik kaynağı olarak hizmet verebileceği görüşünü ortaya koymuşlardır. Bu nedenle, destinasyon pazarlama örgütleri kendi kaynaklarını ve yeteneklerini kullanarak bir dizi rekabet avantaji elde etmek, gastronomi turizm stratejisi geliştirmek ve gastronomi turizmine dikkat çekmek için gastronomiyi turizmde marka imajı olarak desteklemektedir (Telfer 2000; Tellström vd. 2006).

Gastronomi turizminin diğer önemli etkisi de turizm sezonunun uzamasına katkıda bulunmasıdır. Kivela ve Crotts'un (2005) belirttiği gibi gastronomi, diğer seyahat aktiviteleri ve çekiciliklerinin ak- 
sine günün herhangi bir saatinde ve her hava koşulunda elverişli olan bir turizm çeşididir (Mak vd. 2011).

Correia vd. (2010) araştırmalarında, destinasyon yemek kültürünün o yerin tercihinde önemli bir etken olduğunu saptarlarken Harrington (2008) çalışmasında yemek kültürünün destinasyon kimliği bileşeninin önemli parçası olduğunu ortaya koymuştur. Long (2005) ve Ganher (2004) ise araştırmalarında gastronominin ülke kültürü içindeki önemini konu almışlardır.

\section{SONUÇ}

Gastronominin köklü bir bilim olması ile birlikte özellikle de son yıllarda turizm alanında da çekicilik unsuru olarak kullanılmaya başlanması, seyahat motivasyonu olmasina ve bu alanda önemli potansiyel yaratmasına zemin hazırlamıştır. Bu gelişme son on yılda ilgili alanda yapılan araştırma ve çalışmaların sayısına da yansımıştır. Alan araştırmacıları bir taraftan ilgili ülke ya da bölgenin gastronomi açısından avantaj ve dezavantajlarını incelerken diğer taraftan benzer destinasyonlarla karşılaştırmalar yaparak benzerlikleri ve farklılıkları ortaya koymaya yönelmişlerdir.

Genel bir ifadeyle gastronomi turizminden bahsedebilmek için farklı amaçla destinasyonun ziyareti sırasında herhangi bir işletmede yiyecek veya içecek tüketimi yeterli görülmemektedir. Turistlerin birincil ya da diğer seyahat amaçları içerisinde bu etkinliğin yer alması ve destinasyona ulaşımın ardından bu etkinliğin bir parçası olmaları ön koşul olarak kabul edilmektedir. Yiyecek ve içeceklerin tarladan sofraya gelene kadar geçen sürecin bir veya birkaç bölümünde bulunmak ve bu alana ilgi duymak gastronomi turizminin bir açıklaması olarak kabul edilmektedir.

Yapılan araştırmalar gastronomi turizmi açısından büyük ölçekli kitlelerin olmadığını ve ancak niş pazar niteliğinde bulunduğunu göstermektedir. Son yüzyılda araştırma olanaklarının gelişmesi ve beklentilerin değişmesi, turistlerin farklılık arayışlarına da yansımaktadır.

Gastronomi turizmi kavramı literatürdeki yerini alırken bu alanda gelecekte yapılacak bilimsel çalışmalarda nitelik ve nicelik artışı olabileceği söylenebilir. Bu çalışmalar bir taraftan bu alanda farkındalık yaratırken, diğer tarafta kamu ve özel sek- törün yararlanabileceği bir takım verileri de ortaya koyabilecektir. Bu durum alanla ilgili kurum ve kişilerin ilgisini bu yöne çekmesi açısından önem arz etmektedir. Sonuçta, ülkelerin turizmi açısından kullanılabilecek bir çekicilik olarak değerlendirilecek gastronomi, bir bakıma ülkenin mutfak kültürünün de yaşatılmasına katkı sağlayabilecektir.

Gelecekte yapılacak araştırmalarda, ülke ve bölgelerin gastronomi turizmi açısından karşılaştırmasını yapmak veya gelen turistlerin yiyecek-içecek beklentilerini ve memnuniyet düzeylerini ölçmek yeterli olmayabilir. Bu bakımdan gastronominin ilgili destinasyonların tercih edilmesinde ya da seyahat motivasyonunda hangi derecede öneme sahip olduğunun belirlenmesine yönelik araştırmalar mevcut yazına önemli katkılar sağlayabilecektir. Ayrica gastronomiyi birincil seyahat gerekçesi olarak gelen turistlerin temel özelliklerini belirlemeye yönelik araştırmalar da ilgili yazına zenginlik kazandırabilir. Uluslararası yazında son on yılda artan araştırma sayısına rağmen, ulusal yazın oldukça sınırlı durumdadır. Yeni araştırmaların bu alana yönlendirilmesi gastronominin turizm amaç$l_{1}$ kullanılmasına destek sağlayabilecektir.

\section{KAYNAKÇA}

Akgöl Y. (2012). Gastronomi Turizmi ve Türkiye'yi Ziyaret Eden Yabanc1 Turistlerin Gastronomi Deneyimlerinin Değerlendirilmesi (Yayımlanmamış Yüksek Lisans Tezi). Mersin Üniversitesi, Sosyal Bilimler Enstitüsü, Turizm İşletmeciliği Anabilim Dalı.

Alant, K. ve Bruwer, J. (2004). Wine Tourism Behavior in The Context Of a Motivational Framework For Wine Regions And Cellar Doors, Journal of Wine Research, 15 (1): 27-37.

$\mathrm{Au}, \mathrm{L}$. ve Law, R. (2002). Categorical Classification of Tourism Dining, Annals of Tourism Research, 29 (3): 819-833.

Bahçe, S., Yüksek, G., Öney, H. ve Çiçek, D. (2013). Alternatif Turizm. Eskişehir: Açıköğretim Fakültesi Yayınları.

Barkat, M. S. ve Vermignon V. (2006). Gastronomy Tourism: A Comparative Study of two French Regions: Brittany and La Martinique, Sustainable Tourism with Special Reference to Islands and Small States Conference Malta: 25-27 May1s 2006.

Barrere, C., Bonnard, Q. ve Chossat, V. (2009). Luxury Gastronomy As An Attractive Activity For Luxury Tourism. Enometrie XVI - Namur, Session 7, 2009.

Baysal, A. ve Küçükarslan. N. (2003). Beslenme İlkeleri ve Menü Planlaması. Bursa: Ekin Kitabevi.

Belisle, F. (1983). Tourism and Food Production in the Caribbean, Annals of Tourism Research, 10: 497-513.

Bessière, J. (1998). Local Development and Heritage: Traditional Food And Cuisine As Tourist Attractions in Rural Areas, Sociologia Ruralis, 38 (1): 21-34. 
Blakey, C. (2011). Consuming Place: Tourism's Gastronomy Connection, University Of Hawai'i At Hilo, Hawai'i Community College Hohonu, 10: 51-54.

Blichfeldt, B. S. ve Therkelsen, A. (2010). Food and Tourism: Michelin, Moussaka And McDonald's. Tru \& Department Of Culture And Global Studies Aalborg University, Danimarka.

Boniface P. (2003). Tasting Tourism: Traveling for Food and Drink. Ashgate: Ashgate Publishing Limited.

Boyne, S., Hall, D. ve Williams, F. (2003). Policy, Support and Promotion for Food-Related Tourism Initiatives, İçinde Paul W. Lewis ve Bai Bibo (Editörler), Wine, Food, and Tourism Marketing (ss. 131-152). Binghamton (ABD): The Harworth Hospitality Yayınları.

Bratec, M. (2008). Sustaining Through Gastronomy: The Case of Slow Food Movement in Slovenia. Its Impacts on Sociocultural Environments and Tourism Development, Sustaining Quality of Life through Tourism Conference, 24-27 Haziran, İzmir.

Brillat-Savarin, J-A. (1994). La Physiologie du Goût. Penguin, London (Anne Drayton, Trans.; As the Physiology of Taste, 1. Bask1. 1826). London: Penguin.

Brotherton, B. (1999). Toward A Definitive View Of The Nature Of Hospitality And Hospitality Management, International Journal of Contemporary Hospitality Management, 1: 49-57.

Brotherton, B. ve Wood, R. C. (2000). Hospitality and Hospitality Management. İçinde C. Lashley, A. Morrison (Editörler), In Search of Hospitality: Theoretical Perspectives and Debates. (1-17) Butterworth- Heinemann, Oxford.

Can A., Sünnetçioğlu, S. ve Durlu-Özkaya, F. (2012). Füzyon

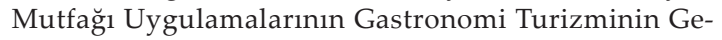
lişimine Katkısı, 13. Ulusal Turizm Kongresi, 6-9 Aralık 2012, Antalya: 873-882.

Canizares, S. S ve Guzman L. T.(2012), Gastronomy as a Tourism Resource: Profile of the Culinary Tourist, Current Issues in Tourism, 15 (3): 229-245.

Chaney, S. ve Ryan, C. (2012). Analyzing the Evolution of Singapore's World Gourmet Summit: An Example of Gastronomic Tourism, International Journal of Hospitality Management, 31: 309-318.

Charters, S. ve Ali-Knight, J. (2000). Who is the Wine Tourist?, Tourism Management, 23 (1): 311-319.

Cheung, S. C. H. (2008). Gastronomy and Tourism A Case Study of Gourmet Country-Style Cuisine in Hong Kong, Asia on Tour: Exploring the Rise of Asian Tourism. Londra: Routledge Yayınları, 264-273.

Cohen, E. ve Avieli, N. (2004). Food in Tourism: Attraction and Impediment, Annals of Tourism Research, 31: 755-78.

Colovic, K. Z., Cerovic Z. ve Beran, M. I. (2012). Strategic Networking Improving Gastronomy in Small Medium Hospitality Enterprises, Tourism \& Hospitality Management Conference Proceedings, 116-125.

Correia, A., Motial, M., Da Costa, F. ve Peres, R. (2008). The Determinants of Gastronomic Tourists' Satisfaction: A Second- Order Factor Analysis, Journal of Food Service, 19: 164-176.

Correia, A., Valle, P. ve Moço, C. (2007). Modeling Motivations and Perceptions of Portuguese Tourists, Journal of Business Research, 60: 76-80.
Çağlı, I. B. (2012). Türkiye'de Yerel Kültürün Turizm Odaklı Kalkınmadaki Rolü: Gastronomi Turizmi Örneği. (Yayımlanmamış Yüksek Lisans Tezi). İstanbul Üniversitesi, Sosyal Bilimler Enstitüsü, Turizm İşletmeciliği Anabilim Dalı.

Çakır, M. (2009). Destinasyon Pazarlamasında Gastronominin Rolü, TÜROFED, 30: 48-50.

Çevik, S. ve Saçıllk, M. Y. (2011). Destinasyonun Rekabet Avantaj1 Elde Etmesinde Gastronomi Turizminin Rolü: Erdek Örneği. 12. Ulusal Turizm Kongresi, 30 Kasım-4 Aralık 2011, 503-515.

Deveci, B., Türkmen, S. ve Avcıkurt, C. (2013). Kırsal Turizm İle Gastronomi Turizmi İliş̧kisi: Bigadiç Örneği, Uluslararası Sosyal ve Ekonomik Bilimler Dergisi, 3: 29-34.

Dilsiz, B. (2010). Türkiye'de Gastronomi ve Turizm İstanbul Örneği (Yayımlanmamış Yükseklisans Tezi). İstanbul: İstanbul Üniversitesi Sosyal Bilimler Enstitüsü Turizm İşletmeciliği Anabilim Dalı.

Du Rand, G. (2003). The Role of Local and Regional Food in Destination Marketing: A South African Situation Analysis. Haworth Yayınları.

Du Rand, G. ve Heath, E. (2006). Towards a Framework For Food Tourism As An Element Of Destination Marketing, Current Issues in Tourism, 9: 206-34.

Durlu-Özkaya, F. ve Can, A. (2012). Gastronomi Turizminin Destinasyon Pazarlamasına Etkisi, Türktarım Dergisi, 206: 28-33.

Eren, S. (2007). Türk Mutfağı ve HACCP Sistemi; Mutfak Profesyonellerinin Haccp Bilgilerinin Ölçülmesi, I. Ulusal Gastronomi Sempozyumu, 4-5 Mayıs 2007, Antalya, 79-83.

Fox, R. (2007). Reinventing the Gastronomic Identity of Croatian Tourist Destinations, International Journal of Hospitality Management, 26: 546-559.

Ganter, H. D. (2004). Changes in Work Organizations in French Top-Quality Restaurants, Business History, 46 (3): 439-460.

Giampiccoli, A. ve Kalis, J. H. (2012). Tourism, Food, And Culture: Community-Based Tourism, Local Food, and Community Development in Mpondoland, Culture, Agriculture, Food And Environment, 34 (2): 101-123.

Gillespie, C. ve Cousins, J. A. (2001). European Gastronomy into the 21st Century, Burlington (USA): Butterworth- Heinemann.

Göker, G. (2011). Destinasyon Çekicilik Unsuru Olarak Gastronomi Turizmi: Balıkesir İli Örneği. (Yayımlanmamış Yüksek Lisans Tezi). Balıkesir Üniversitesi Sosyal Bilimler Enstitüsü, Turizm İşletmeciliği Anabilim Dalı.

Göynüşen, S. E. (2011). Edirne'deki Gastronomik Kültürün Kentin Pazarlama ve Markalaşmasına Etkileri. (Yayımlanmamış Yüksek Lisans Tezi). Trakya Üniversitesi, İşletme Anabilim Dalı.

Gross, M. J., Brien, C. ve Brown, G. (2008). Examining The Dimensions Of A Lifestyle Tourism Destination. International Journal of Culture, Tourism and Hospitality Research, 2 (1): 44-66.

Guzmán, T. L. ve Cañizares, S. S. (2011). Gastronomy, Tourism and Destination Differentiation: A Case Study in Spain. Academic Research Centre of Canada.

Hacısüleyman, Y. (1987) Otelcilik ve Gastronomi Alanında İş Organizasyonu ve Yönetimi. (Yayımlanmamış Yükseklisans Tezi). İstanbul Üniversitesi, Sosyal Bilimler Enstitüsü. Turizm İşletmeciliği Anabilim Dalı. 
Hall, C. M. (2006). Culinary Tourism And Regional Development: From Slow Food To Slow Tourism?, Tourizm Review Intenational, 9 (4): 303-306.

Hall, C. M. ve Macionis, N. (1998). Tourism and recreation in rural areas İçinde R. W. Butler, C. M. Hall, \& J. Jenkins, Wine Tourism in Australia and New Zealand. (ss. 197-224). New York: John Wiley \& Sons.

Hall, M. ve Mitchell, R. (2000). Wine Tourism in the Mediterranean: a Tool for Restructuring and Development, Thunderbird International Business Review, 42 (4): 445- 465.

Hall, M. ve Sharples, L. (2003). Food Tourism Around The World, İçinde M. Hall, L. Sharples, R. Mitchell, N. Macionis ve B. Cambourne, The Consumption of Experiences or the Experience of Consumption? An Introduction to the Tourism of Taste (ss. 1-25). Londra: Butterworth Heinemann.

Hamamcibaşı, F. Ü. (2006). Yiyecek Turizmin ve Yiyecek Turizmini Açısından Bozcaada'nın Kaynakları. (Yayımlanmamış Yüksek Lisans Tezi). Çanakkale Onsekiz Mart Üniversitesi, Sosyal Bilimler Enstitüsü, Turizm İşletmeciliği Anabilim Dalı.

Harrington, R. J. ve Ottenbacher, M. C. (2010). Culinary Tourism: A Case Study of the Gastronomic Capital, Journal of Culinary Science \& Technology, 8: 14-32.

Hashimoto, A. ve Telfer, D. J. (2006). Selling Canadian Culinary Tourism: Branding the Global and the Regional Product, Tourism Geographies: An International Journal of Tourism Space, Place and Environment, 8 (1): 31-55.

Hatipoğlu, A. (2010). İnançların Gastronomi Üzerindeki Etkileri: Bodrum'daki Beş Yıldızlı Otellerin Mutfak Yöneticilerinin Görüşlerinin Belirlenmesine Yönelik Bir Araştırma. (Yayımlanmamış Yüksek LisansTezi). Sakarya Üniversitesi Sosyal Bilimler Enstitüsü, Turizm İșletmeciliği Anabilim Dalı.

Henderson, J. C. (2009). Food Tourism Reviewed, British Food Journal, 11 (4): 317-326.

Hillel, D., Belhassen, Y. ve Shani, A. (2013). What Makes Gastronomic Destination Attractive? Evidence from the Israeli Negev, Tourism Management, 36: 200-209.

Hjalager, A. M. ve Johansen, H. P. (2013). Food Tourism in Protected Areas- Sustainability for Producers, the Environment and Tourism?, Journal of Sustainable Tourism, 21 (3):417-433.

Hjalager, A. M. ve Corigliano, M., A. (2000). Food for Tourists Determinants of an Image, International Journal of Tourism Research, 2: 281-293.

Hobsbawm, E. ve Ranger T. (1983). The Invention of Tradition. Cambridge: Cambridge University Yayınları.

Horng, J. S. ve Tsai, C. T. (2012a). Culinary Tourism Strategic Development: An Asia-Pacifi C Perspective, International Journal of Tourism Research, 14: 40-55.

Horng, J. S. ve Tsai, C. T. (2012b). Exploring Marketing Strategies For Culinary Tourism in Hong Kong And Singapore, Asia Pacific Journal Of Tourism Research, 17 (3): 277-300.

Horng, J. S. ve Tsai, C. T. (2012c). Government Websites for Promoting East Asian Culinary Tourism: A Cross-National Analysis, Tourism Management, 31 (1): 74-85.

Hussain, Z., Lema, J. ve Agrusa, J. (2012). Enhancing The Cultural Tourism Experience Through Gastronomy in the Maltives, Journal of Tourism Challenges and Trends, 5 (2): 71-84
Ignatov, E. ve Smith, S. (2006). Segmenting Canadian Culinary Tourist, Current Issues in Tourism, 9 (3): 235-255.

İlhan, I. (2011). Gastronomi: Yeme-İçme Bilim ve Sanatı. http:// yemek.meltem.gen.tr/?yazi=19, Erişim tarihi: 1 Mayıs 2013.

Ismailov, J., Vilas, S. F. ve Sanchez, E. (2010). Tourist Classifications in Gastronomy of Santiago de Compostela: Based On The Data Collected From Santiago. Tapas Contest Santiago de Compostela Üniversitesi Tapas Yarışması, İspanya.

Joppe, M. (2003). Optimising Tourism Destination Development in Canada, International Journal of Contemporary Hospitality Management, 15 (6): 308-311.

Josiam, B., Mattson, M. ve Sullivan, P. (2004). The Historount: Heritage Tourism at Mickey's Dining Car, Tourism Management, 25: 453-461.

Karim, A. S. ve Chi, C. G. Q. (2010). Culinary Tourism as a Destination Attraction: An Empiricial Examination of Destinations Food Image, Journal Of Hospitality Marketing \& Management, 19 (6): 531-555.

Karim, S. A. (2006). Culinary Tourısm as a Destınatıon Attract1on: An Empirical Examination of The Destination's Food Image And Information Sources. Oklahama: Bachelor of Science in Hotel \& Restaurant Management.

Kesici, M. (2012). Kırsal Turizme Olan Talepte Yiyecek ve İçecek Kültürünün Rolü, KMÜ Sosyal ve Ekonomik Araştırmalar Dergisi, 14 (23): 33-37.

Kim, Y. G., Eves, A. ve Scarles, C. (2007). Building a Model of Local Food Consumption on Trips and Holidays: A Grounded Theory Approach, International Journal of Hospitality Management, 28 (3): 423-431.

Kivela, J. ve Crotts, J. C. (2006). Tourism and Gastronomy: Gastronomy's Influence on How Tourists Experience a Destination, Journal of Hospitality and Tourism Research 30: 354-77.

Kivela, J. ve Crotts, J.C. (2005). Gastronomy Tourism: A Meaningful Travel Market Segment, Journal of Culinary Science \& Technology, 4 (2/3): 39-55.

Kumar, M. (2013). Gastronomy Tourism Potential: A Case Study Of Northern India, International Journal of Rewievs, Surveys and Research, 2 (1): 1-16.

Küçükaltan, G. (2009). Küreselleşme Sürecinde Gastronomide Yöresel Tatların Turistlerin Destinasyon Tercihlerine ve Ülke Ekonomilerine Etkileri. 3. Ulusal Gastronomi Sempozyumu, 17-18 Nisan 2009, Antalya.

Lakıcevic, M., Zarevac, M. ve Pantic, N. (2012). Gastronomic Festivals In Rural Regions of Serbia, Megatrend Review, 9: $73-82$.

Lang, J. H. (1988). Larousse Gastronomique. Londra: Crown.

Law, R., Cheung, C. ve Lo, A. (2004). The Relevance of Profiling Travel Activities for Improving Destination Marketing Strategies. International Journal of Contemporary Hospitality Management, 16 (6): 355-362.

Lin, Y. C., Pearson, E. T. ve Liping, A. (2011). Food As A Form Of Destination Identitiy: A Tourism Destination Brand Perspective, Tourism And Hospitality Research, 11 (1): 30-48.

Ling, Q. L., Karim, M., Othman, M., Adzahan, N. M. ve Ramachandran, S. (2010). Relationships Between Malaysian Food Image Tourist Satisfaction and Behavioural Intention, World Applied Sciences Journal 10, Special Issue of Tourism \& Hospitality, 164-171. 
Londoño, M. D. P. L. (2009). Gastronomy Tourism: An Opportunity For Local Development In Catalonia? A Stakeholder Analysis. Catalonia Gastronomy, http://www-sre.wuwien.ac.at/ersa/ersaconfs/ersa11/e110830aFinal01083.pdf, Erişim tarihi: 3 Şubat 2013

Long, M. L. (2005). Culinary Tourism. ABD: The University Press Of Kentucky.

Macionis, N. ve Cambourne, B. (2002). Food Tourism Around The World, İçinde M. Hall, L. Sharples, R. Mitchell, N. Macionis ve B. Cambourne (Editörler), Consuming Places: the Role of Food, Wine and Tourism in Regional Development (ss. 26-59). Londra: Butterworth Heinemann.

Mak, A. H. N., Lumbers, M., Eves, A. ve Chang, R. C. Y. (2011). Factors Influencing Tourist Food Consumption. http:// www.sciencedirect.com/science/journal/02784319, Erişim tarihi: 1 Şubat 2013.

Marris, T. ( 1986). Does Food Matter, The Tourism Review, 41 (40): $17-20$

McGee, H. (2004). On Food and Cooking: The Science and Lore of the Kitchen. ABD: Scribner.

McKercher, B., Okumus, F. ve Okumuş, B. (2008). Food Tourism as a Viable Market Segment: It's All How You Cook the Numbers, Journal Of Travel \& Tourism Marketing, 25 (2):137- 148.

Mil, B. (2009). Yemek Pişirmeden Gastronomiye Uzanan Bakıș Açısıyla Küreselleşen Dünya, 3. Ulusal Gastronomi Sempozyumu, 17-18 Nisan 2009, Antalya.

Mitchell, R. ve Hall, M. (2003). Consuming Tourists: Food Tourism Consumer Behaviour, İçinde M. Hall (Editör), Food Tourism Around The World: Management Of Development And Markets (ss. 60-62), Great Britain. Elseiver.

Molz, J. G. (2007). Eating Difference: The Cosmopolitan Motilities of Culinary Tourism, Space And Culture, 10 (1): 77-93.

Nield K, Kozak, M. ve LeGrys, G. (2000). The Role Of Food Service in Tourist Satisfaction, Hospitality Management, 19 (3): 75-84

Nilssona, J. H., Svard, A. C., Widarsson, A. ve Wirell, T. (2011). 'Citta'slow' Eco-Gastronomic Heritage As A Tool For Destination Development, Current Issues in Tourism, 14 (4): 373-386.

Okumuş, B., Okumuş, F. ve McKercher, B. (2007). Incorporating Local and International Cuisines in the Marketing of Tourism Destinations: The Cases of Hong Kong and Turkey, Tourism Management, 28 (1): 253-261.

Özçil, A. (2012). Bir Mutfak, Dünya Kadar Lezzet. http://www. kibrisgazetesi.com/printa.php?col=146\&art=19749, Erişim tarihi: 1 Mayıs 2013.

Pedersen, T. (2008). Molecular Gastronomi. Kopenhag: Nyt Nordisk Yayınları.

Quan, S. ve Wang, N. (2004). Towards a Structural Model of the Tourist Experience: An Illustration from Food Experiences in Tourism, Tourism Management, 25 (3): 297-305.

Reynolds, P. (1993). Culinary Heritage in The Face of Tourism, Progress in Tourism Recreation and Hospitality Management, 6: 189-194.

Richards, G. (2002). Tourism Gastronomy. İçinde A-M. Hjalager ve G. Richards (Editörler), Gastronomy: and Essential Ingredient in Tourism Production and Consumption? (320) Londra: Routledge.

Santich, B. (2004). The Study of Gastronomy and Its Relevance to Hospitality Education and Training, Hospitality Management, 23: 15-24.
Scarpato, R. (2000). New Global Cuisine: the Perspective of Postmodern Gastronomy Studies'. (Yayımlanmamış Yüksek Lisans Tezi). Melbourne: RMIT Üniversitesi.

Scarpato, R. (2002). Tourism Gastronomy, İçinde A-M Hjalager ve G. Richards (Editörler). Gastronomy as a Tourist Product: The Perspectives of Gastronomy Studies. (51-59) Londra: Routledge.

Sheldon, P. ve Fox, M. (1988). The Role of Foodservice in Vacation Choice and Experience: A Cross-Cultural Analysis, Journal of Travel Research, 26 (30): 9-15.

Shenoy, S. S. (2005). Food Tourism And The Culinary Tourist. Clemson Üniversitesi, Felsefe Anabilimdalı Yüksek Lisans Tezi Philosopy.

Sims R. (2009). Food, Place and Authenticity: Local Food and the Sustainable Tourism Experience, Journal of Sustainable Tourism, 17 (3): 312-336.

Smith, S. ve Xiao, H. (2008). Culinary Tourism Supply Chains: A Preliminary Examination, Journal of Travel Research, 46: 289-299.

Soner, F. (2013). Gastronomy Tourism: A Solution For Small Cities Marketing And Regional Development. (Yayımlanmamış Yüksek Lisans Tezi). Yeditepe Üniversitesi, Gastronomi ve Mutfak Sanatları Anabilim Dalı.

Surenkok, A., Baggio, R. ve Corigliano, R. M. (2010). Gastronomy And Tourism in Turkey: The Role of ICTs, Proceedings Of The International Conference in Lugano, İsviçre, 10-12 Şubat 2010.

Telfer, D. ve Wall, G. (1996). Linkages Between Tourism and Food Production, Annals of Tourism Research, 23 (3): 635653.

Tellström, R., Gustafasson, I. B. ve Mossberg, L. (2006). Consuming Heritage: The Use of Local Food Culture in Branding, Place Branding \& Public Diplomacy, 2 (2):130-143.

Tez, Z. (2012). Lezzetin Tarihi. İstanbul: Hayykitap.

Torres, R. (2003). Linkages Between Tourism and Agriculture in Mexico, Annals of Tourism, 30 (3): 546-566.

Westering, J. (2007). Heritage and Gastronomy: The Pursuits Of The 'New Tourist', International Journal of Heritage Studies, 5 (2): 75-81.

Wilkins, J. ve Hill, S. (1994). The Life of Luxury. Blackawton, Totnes: Prospect Books.

Williams, P. (2001). The Evolving Images of Wine Tourism Destinations, Tourism Recreation Research, 28 (2): 3-10.

Wolf, E. (2006). Culinary Tourism the Hidden Harvest. ABDLowa: Kendall/Hunt Yayıncılık Şirketi.

Wood, N. E. (2001). The Interdependence Of Farming And Tourism in Vermont: Quantifying The Value Of The Farm Mindscape. (Yayımlanmamış Yüksek Lisans Tezi). Department of Community Development and Applied Economics, University of Vermont.

Yurtseven, H. R. (2011). Sustainable Gastronomic Tourism in Gökçeada (Imbros): Local and Authentic Perspectives, International Journal of Humanities and Social Science, 1 (18): 17-26.

Yüncü, H. R. (2010). Sürdürülebilir Turizm Açışından Gastronomi Turizmi ve Perşembe Yaylası, İçinde S. Şengel (Editör), 10. Aybastı - Kabataş Kurultayı Yerel Değerler ve Yayla Turizmi, (ss. 27-34), Ankara: Detay Yayıncılık. 